\title{
A vocação exportadora do Rio Grande do Sul: uma avaliação por meio do efeito fronteira
}

\author{
Sérgio Leusin Jr. \\ Professor de Economia da \\ Universidade do Vale do Rio dos Sinos (UNISINOS) \\ André Filipe Zago de Azevedo \\ Professor do Mestrado em Economia da \\ Universidade do Vale do Rio dos Sinos (UNISINOS) \\ Bolsista de Produtividade em Pesquisa do CNPq. \\ Marcos Tadeu Caputi Lélis \\ Professor do Mestrado em Economia da \\ Universidade do Vale do Rio dos Sinos (UNISINOS)
}

\section{Palauras-chave \\ efeito fronteira, \\ modelo gravitacional, \\ integração regional.}

Classificação JEL R12, R15, F15.

\section{Key-Words \\ Border Effect, Gravity Model, Regional Integration}

JEL Classification R12, R15, F15

\section{Resumo}

O Rio Grande do Sul tem se notabilizado pelo elevado volume de suas exportaçóes, sendo atualmente o terceiro maior estado exportador brasileiro. Este artigo busca examinar o viés exportador do estado através do chamado "efeito fronteira" para o período 1997-2002. Esse efeito foi estimado empiricamente, utilizando-se dados agrupados e dados em painel, em um modelo gravitacional com os 27 estados brasileiros e 40 países. Os resultados apontam para a inexistência de um viés de comércio para os demais estados brasileiros; portanto as fronteiras nacionais não representariam custo maior para as exportaçóes do Rio Grande do Sul em relação aos demais estados. Possíveis causas da inexistência do viés doméstico de comércio do Rio Grande do Sul podem estar relacionadas à maior proximidade geográfica do estado com outros países, principalmente os do Mercosul, às preferências comerciais garantidas pelo bloco, bem como ao perfil de suas exportaçóes, baseadas principalmente em produtos primários.

\section{Abstract}

Rio Grande do Sul is one of the most important states in terms of exports in Brazil, and is currently the third largest exporter. This paper examines the export bias of the state through the so-called border effect in the period 1997-2002. This effect, defined as the negative impact of national borders on trade volumes, was estimated empirically, using a gravity model with both pooled and panel data with all 27 Brazilian states and 40 countries. The results suggest that borders do not represent an additional cost to the state's international trade. Possible explanations for the absence of the border effect are related to the proximity of Rio Grande do Sul with other countries, especially those from MERCOSUR, to the trade preferences granted by the bloc and to the state's export profile, based on primary products. 


\section{1_Introdução}

As fronteiras nacionais parecem estar perdendo relevância, na medida em que o progresso tecnológico tem diminuído significativamente os custos de transporte e de comunicação nas últimas décadas. Além disso, as barreiras tarifárias e não tarifárias têm sido reduzidas multilateral e preferencialmente, desde que um número cada vez maior de países tem se engajado nas negociações da Organização Mundial de Comércio (OMC) e na formação de blocos econômicos. ${ }^{1}$ Tal aumento da integração econômica internacional, que tem levado os fluxos de comércio a crescer mais rapidamente que o PIB dos países, confirmaria essa impressão. ${ }^{2}$

Conforme destaca Frankel (1997), é usualmente aceito que, em termos de comércio internacional, o mundo está ficando cada vez menor. Alguns economistas chegam a concordar com Ohmae (1990), que afirma que as fronteiras nacionais teriam desaparecido efetivamente.
Ou, ao menos, que o impacto negativo das fronteiras nacionais sobre o volume de comércio, o chamado "efeito fronteira”, teria sido dramaticamente reduzido. Ou seja, o processo que se convencionou chamar de "globalização" estaria tornando menores os custos associados ao comércio internacional, que não seriam observados no comércio intranacional.

Esses custos podem ser inerentes à diferença de gosto entre as populaçóes, que, por sua vez, pode ser originada pela diversidade de renda per capita entre as economias, ou ainda, por diferenças na língua e na cultura, ou de política comercial. Em relação ao processo de homogeneização cultural e econômica promovido pela globalização, Baldwin e Martin (1999) destacam a significativa redução dos custos de transportes e comunicação como fatores determinantes para o vigor apresentado no crescimento das exportaçôes mundiais na história recente. ${ }^{3}$

$\begin{array}{ll}{ }^{\text {Segundo Rodriguez (2007), a }} & 2 \text { Segundo dados da OMC } \\ \text { tarifa média das importaçóes } & (2010), \text { nos 25 anos após a 2a } \\ \text { mundiais, entre 1990 e 2002, } & \text { Guerra Mundial, o comércio } \\ \text { passou de 10,5\% para 6\%, e } & \text { mundial cresceu em média } \\ \text { o grau de abertura mundial, } & 8 \% \text { ao ano, ao passo que } \\ \text { de 75,2\% para } 86,8 \% \text {. O grau } & \text { o crescimento econômico } \\ \text { de abertura é mensurado } & \text { mundial foi em média de } \\ \text { mediante a razáo entre a } & 5 \% \text { ao ano. }\end{array}$
soma das exportaçóes e a das importaçóes pelo PIB.

\footnotetext{
${ }^{3}$ Bairoch (1989) apud Baldwin e Martin (1999) observou que, em 1830, o custo de transporte do ferro e do trigo, por exemplo, representava, respectivamente, $92 \%$ e $79 \%$ do custo de produção desses bens, caindo para $19 \% \mathrm{e}$ 27,5\% em 1910.
} 
${ }^{4}$ Grau de abertura mensurado por meio da corrente de comércio dividido pelo PIB.
O modelo gravitacional tem sido o principal instrumento utilizado pela literatura para medir esse viés doméstico do comércio ou efeito fronteira (por exemplo, McCallum, 1995; Silva et al., 2007). A equação gravitacional controla os fatores que determinam o fluxo bilateral de comércio, incluindo PIB e distância, além de um conjunto de variáveis econômicas, geográficas e culturais, permitindo estimar o efeito fronteira, por meio de uma variável dummy, que captaria o impacto adicional de comércio específico ao par de estados/países. McCallum (1995) foi o precursor a estimar o impacto das fronteiras no padrão de comércio de dois países contíguos. O autor verificou que, mesmo para países com renda semelhante e integrantes de um acordo de livre comércio, como é o caso dos EUA e do Canadá, as barreiras nacionais ocasionaram grande viés doméstico dos fluxos de comércio entre esses países. O efeito fronteira existente entre o Canadá e os EUA, em 1988, revelou que o comércio entre duas províncias canadenses seria 22 vezes maior que o comércio entre uma província e um estado dos Estados Unidos. Silva et al. (2007), por sua vez, buscaram medir a magnitude do efeito fronteira para o Brasil. Os resultados encontrados mostraram que o comércio entre dois estados brasileiros, em 1999, era
37 vezes maior que o comércio internacional desses estados.

Dessa forma, pode-se argumentar que, mesmo ocorrendo um processo de integraçáo internacional, o Brasil ainda apresentaria elevado impacto de suas fronteiras no comércio internacional. Um aspecto importante do efeito fronteira para as regiôes brasileiras é que a sua magnitude mostra variação extremamente elevada entre as regiōes, sendo significativamente maior nas regióes Norte e Nordeste, em relaçáo às regióes Sul e Sudeste (por exemplo, Daumal; Zignago, 2005; Leusin Jr.; Azevedo, 2009). Nesses trabalhos, a Região Sul apresentou o menor viés doméstico de seus fluxos comerciais, indicando o maior grau de abertura dessa regiáo para o exterior. Tais resultados vão ao encontro da magnitude do grau de abertura ${ }^{1}$ dos estados da Região Sul encontrados por Souza (2003), em que o Rio Grande do Sul (22,2\%), Santa Catarina (20,5\%) e o Paraná (19,2\%) figuram, respectivamente, como terceiro, quarto e sétimo no ranking brasileiro com maior grau de abertura para o período entre 1991 e 2000.

Este artigo tem como objetivo principal, portanto, mensurar a magnitude do efeito fronteira para o estado do Rio Grande do Sul, para o período 1997-2002, o único estado com informaçóes consolidadas disponíveis para o comércio interestadual no país. Está dividido, além desta in- 
trodução, em três seções. $\mathrm{Na}$ seção 2, são apresentados os resultados empíricos encontrados na literatura econômica sobre o efeito fronteira, baseados no modelo gravitacional, com ênfase nos trabalhos que estimaram o efeito fronteira no Brasil. Na seção 3, são mostrados os dados, a abordagem econométrica e os resultados do efeito fronteira, estimados mediante o modelo gravitacional, para o estado do Rio Grande do Sul, para o período 1997 2002. A seção 4 aponta as conclusóes.

\section{0 efeito fronteira}

A maior integração econômica entre os países tem criado uma imagem que as fronteiras nacionais estariam perdendo relevância até o ponto de se tornarem irrelevantes, ou seja, para um estado de um país, seria indiferente exportar para outro estado do próprio país ou para o exterior, controlando-se para as variáveis econômicas, geográficas e culturais que determinam o comércio internacional. Nesse contexto, a partir da década de 1990, começou a surgir uma série de estudos que buscou, por meio do modelo gravitacional, mensurar e analisar o impacto das fronteiras sobre o padrão de comércio internacional e intranacional (McCallum, 1995; Helliwell, 1998; Hidalgo; Vergolino, 1998; Nitsch, 2000; Anderson; Wincoop,
2003; Daumal; Zignago, 2005; Gil-Pareja et al., 2005; Silva et al., 2007).

Graças a sua capacidade de explicar os fluxos bilaterais de comércio, o modelo gravitacional tem sido bastante utilizado para mensurar o viés doméstico dos fluxos de comércio, ou seja, medir qual é a intensidade do viés de comércio intranacional vis-à-vis o comércio internacional ou o efeito fronteira internacional. Para tal propósito, são introduzidas dummies que assumem valor igual a 1 (um), quando o comércio é entre estados/províncias de um mesmo país, e 0 (zero), quando o comércio é internacional. Desta forma, encontra-se o coeficiente que mede o tamanho do viés de comércio entre os estados de um país comparativamente com o comércio externo. $\mathrm{O}$ viés doméstico pode ser causado por uma série de fatores, tais como a preferência dos consumidores por produtos nacionais e a política comercial externa do país. ${ }^{5}$

O trabalho inicial deve-se a McCallum (1995), que utilizou dados de 1988 de exportaçốes entre as províncias do Canadá e os estados dos Estados Unidos, com o objetivo de comparar o comércio intranacional do Canadá com as exportações daquele país para os Estados Unidos. Dessa maneira, o autor buscou mensurar o tamanho do viés doméstico

\footnotetext{
${ }^{5}$ Este coeficiente também pode ser interpretado como uma mensuração alternativa do grau de acesso a mercados, ou seja, mede o quanto os custos de comércio associados às fronteiras interferem nos fluxos de comércio internacionais.
} 
existente no Canadá, quando os fluxos de comércio entre as províncias são comparados com o comércio entre províncias e estados americanos de similar tamanho e distância. Para tanto, o autor selecionou 10 províncias canadenses e 30 estados norte-americanos, que seriam os 20 estados mais populosos, mais todos os estados americanos que fazem divisa com

$$
L n X_{i j}=\beta_{0}+\beta_{1} L n Y_{i}++\beta_{2} \operatorname{Ln} Y_{j}+\beta_{3} L n D I S T_{i j}+\beta_{4} D u m m y_{i j}+\varepsilon_{i j}
$$

onde:

$\mathrm{X}_{\mathrm{ij}}$ : exportaçóes nominais do país $\mathrm{i}$ para o país j;

$\mathrm{Y}_{\mathrm{w}}$ : PIB nominal dos países i e j;

DIST $_{\mathrm{ij}}$ : distância entre os países i e j;

\footnotetext{
${ }^{6}$ Segundo o autor, a amostra dos estados americanos (30 estados) correspondia a $90 \%$ do comércio do Canadá com os EUA, no período examinado.

${ }^{7}$ Em sete casos, não havia registro de comércio, deixando a amostra final com 683 observaçôes.

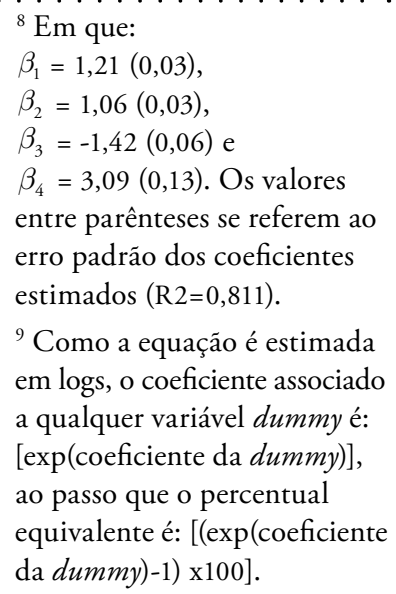

o Canadá. ${ }^{6}$ Assim, sua amostra era composta de 690 observaçóes $(90=10 \times 9$, referente ao comércio interprovíncias, mais $600=10 \times 30 \times 2$, referente ao comércio entre províncias do Canadá e estados americanos). ${ }^{7}$ Desta forma, a regressão estimada pelo autor, através de Mínimos Quadrados Ordinários (MQO), foi: 
Com base nesse resultado, seria possível afirmar que as fronteiras nacionais continuariam sendo um obstáculo importante para os fluxos de comércio internacionais. Tais resultados mostram não apenas a importância das fronteiras para o comércio, mas constituem um desafio para algumas hipóteses comumente feitas sobre a importância do comércio interestadual e internacional, tornando questionável a possibilidade do ajustamento de preços através da arbitragem internacional. ${ }^{10}$ Além disso, deve-se ressaltar que o resultado é no mínimo paradoxal, uma vez que Canadá e EUA são países com culturas de consumo semelhantes, compartilham uma fronteira seca e já haviam firmado alguns acordos bilaterais de comércio entre si, em 1988.

Estendendo os resultados apresentados acima e utilizando a mesma equação de McCallum (1995), Helliwell (1998) questiona qual o padrão de comércio de Quebec (província canadense) comparando com outras províncias do país. Os resultados, baseados em dados revisados para 1988,1989 e 1990 , em uma abordagem por MQO, mostram que, enquanto uma província típica comercializa 20 vezes mais com outras províncias do que com os estados americanos de semelhante tamanho e distância, para Quebec o múltiplo é ainda maior, isto é, 26 vezes. Assim, o comércio entre Quebec e os EUA parece, segundo o autor e confirmando os resultados de McCallum (1995), uma alternativa menos viável do que o comércio entre Quebec e o resto do Canadá.

Anderson e Wincoop (2003), utilizando o modelo gravitacional, revisaram novamente a relação comercial entre Canadá e EUA em uma abordagem por Regressóes Aparentemente Não Relacionadas (SUR - Seemingly Unrelated Regressions) e encontraram um valor diferente daqueles obtidos por McCallum (1995) e Helliwell (1998). Os autores chegaram a um valor inferior, de 16,4. Além disso, também estimaram o efeito fronteira para uma perspectiva dos EUA. O coeficiente encontrado do viés doméstico para os Estados Unidos foi significativamente inferior ao encontrado para o Canadá, de apenas 1,50 .

Neste artigo, os autores inovam ao incluir uma segunda série de resultados obtidos com base em uma equação gravitacional mais elaborada, acrescentando a distância relativa ponderada pelo PIB das economias. Para essa nova equação, eles adicionaram variáveis que buscavam captar o custo de oportunidade (ou resistência multilateral ao comércio) de se estar exportando do estado "i” para o estado “j”, assim como o custo de oportunidade de o estado “j” estar comprando de "i”.

\footnotetext{
${ }^{10} \mathrm{~A}$ argumentação da possibilidade da não ocorrência da arbitragem de preços é um dos seis enigmas da economia internacional observados por Obstfeld e Rogoff (2000).
} 
Ou seja, quando um estado "i" comercializa com o estado “j”, ele está abrindo mão de comercializar com outros estados. Desta forma, essas novas variáveis sugeridas pretendem captar esse efeito, assim como atenuar as distorçóes ocorridas por estados isolados geograficamente ou significativamente desiguais em suas rendas.

Assim, os autores revisaram a equação de gravidade usada por McCallum (1995) e buscaram explicar as razóes para os resultados obtidos. Segundo os autores, dois fatores contribuíram para a obtenção de um viés doméstico tão significativo para o comércio Canadá-EUA. Primeiramente, argumentam que o padrão de comércio do Canadá com os EUA é, em grande parte, explicado pela reduzido tamanho do Canadá se comparado à economia dos EUA. Nesse contexto, insere-se tanto a maior diversidade de produtos existente nos EUA quanto as peculiaridades culturais e geográficas verificadas nas principais províncias canadenses (movimentos separatistas em Quebec, isolamento geográfico entre o lado leste e o oeste, etc.). A segunda linha de explicação para o significativo valor encontrado do viés doméstico de comércio canadense é a ausência de variáveis que expressem a resistência multilateral ao comércio nos modelos que o precederam. De qualquer forma, valendo-se dos estudos de McCallum (1995), Helliwell (1998) e Anderson e Wincoop (2003), pode-se dizer que a magnitude do efeito fronteira entre Canadá e EUA é bastante elevada, com as províncias canadenses comercializando entre 16 e 26 vezes mais com outras províncias do Canadá do que com estados norte-americanos de similar tamanho e distância.

Para o caso da Uniáo Europeia (UE), também se esperava a priori que o efeito fronteira fosse insignificante, dado que o bloco é uma região profundamente integrada, tanto domesticamente como internacionalmente. Contudo, Nitsch (2000) sinalizou o contrário, ao mensurar o impacto das fronteiras nacionais no comércio internacional dos países da UE. Através do modelo gravitacional, estimado de acordo com uma abordagem por Regressores Aparentemente não Relacionados (SUR) com dados dos fluxos comerciais internacionais e intrabloco para o período compreendido entre 1979 e 1990, o autor encontrou um viés doméstico igual a 10. Isso significa dizer que, após controlar para as variáveis do modelo gravitacional, os fluxos comerciais entre os países integrantes da UE eram 10 vezes maiores que os fluxos comerciais desses países para outras naçóes não integrantes do bloco. Os resultados encontrados pelo autor evidenciam a importância das 
fronteiras regionais para blocos econômicos com elevado grau de integração econômica.

Gil-Pareja et al. (2005) analisaram o impacto do efeito fronteira na Espanha mediante um modelo gravitacional com dados do comércio intranacional e internacional para o período de 1995 a 1998. Os autores buscaram estimar também o efeito fronteira para cada uma das 17 regióes espanholas. Para tanto, utilizaram informações do comércio entre as regiōes, assim como o comércio internacional de cada regiáo para 27 países da OCDE. Os resultados indicam que, após controlar para as variáveis do modelo, as regióes espanholas comercializam cerca de 22 vezes mais com outras regióes da Espanha do que com os países da OCDE. Eles observam que o resultado para o efeito fronteira da Espanha é semelhante ao encontrado por McCallum (1995) e também que o viés doméstico dos fluxos comerciais varia significativamente entre as regióes espanholas. Madri, por exemplo, no centro do país, comercializa nove vezes mais com outras regióes espanholas do que com o exterior; já para Cantabria, no extremo norte do país, o viés doméstico é igual a 53 . As ilhas Balearic apresentam o maior impacto das fronteiras sobre os fluxos de comércio (59 vezes), seguidas por Extre- madura (42 vezes) e Asturias (41 vezes). Excluindo esses resultados extremos, pode-se observar que o viés doméstico para a maioria das regióes espanholas situa-se entre 14 e 30 vezes. Os resultados apresentados pelos autores mostram que o viés doméstico, além de não ser necessariamente uniforme para regióes de um país, pode variar significativamente entre elas. Segundo os autores, tais resultados podem ser explicados pela geografia da Espanha, assim como pelas significativas diferenças na estrutura das firmas entre as regióes espanholas.

\section{1_O efeito fronteira no Brasil}

Alguns trabalhos recentes buscaram estimar o efeito fronteira para a economia brasileira. O maior problema é a ausência de dados referentes aos fluxos comerciais entre os estados do Brasil, também por vias internas é um importante instrumento para avaliar as relações comerciais entre os estados, bem como o grau de (in) dependência econômica desses. Contudo, a produção sistemática e continuada das informaçôes relativas às operaçóes de comércio por vias internas é precária ou inexistente. Segundo Vasconcelos e Oliveira (2006), existem informaçōes consolidadas para as décadas de 1940, 1960, $1970 \mathrm{e}$ 1980 e para os anos de 1991, 1996 e 1999. 
${ }_{11}$ Os autores náo consideraram Tocantins para a estimação do efeito fronteira.
Silva et al. (2007) analisaram o efeito fronteira para o mercado brasileiro para o ano de 1999, com base nos dados da matriz de comércio interestadual obtidas de Vasconcelos (2001). O modelo utiliza variáveis como a diferença entre os PIBs per capita dos estados e dos países, assim como uma variável dummy que assume o valor unitário no caso da adjacência entre estados brasileiros ou países, e zero, caso contrário. Utilizando-se de dados de corte seccional, em um modelo gravitacional, com todos os estados brasileiros mais o Distrito Federal e 40 países, os autores encontraram um viés doméstico consideravelmente alto para os padróes observados na literatura econômica. Controlando as variáveis "distância" e "tamanho" das economias, o viés doméstico dos fluxos de comércio do Brasil mostrou-se 37,7 vezes maior do que para fora do país. Entre as justificativas para um viés dessa magnitude, os autores citam o baixo grau de substituição entre os produtos domésticos e estrangeiros e também as grandes barreiras ainda existentes ao comércio internacional.

Além disso, Moreira e Correa (1997) sinalizaram que fatores geográficos, como o tamanho do território e a distância em relação aos principais mercados, assim como o tamanho da população brasileira, contribuem para uma baixa internacionalização dos fluxos comerciais brasileiros. Em todas as estimativas apresentadas acima, tanto para Canadá, União Europeia e Brasil, nota-se ainda a importância das fronteiras nacionais para a determinação dos fluxos comerciais.

Daumal e Zignago (2005) propóem-se a medir o efeito fronteira internacional e intranacional para o Brasil, entre os anos de 1991 a 1999. Para tanto, os autores utilizam duas dummies, "home" e "Brasil", onde a primeira capta a preferência dos estados brasileiros pelo comércio interno, ou seja, entre municípios do mesmo estado, e a segunda dummy capta a preferência pelo comércio entre os estados brasileiros, e não com o exterior, ou seja, o efeito fronteira internacional. De forma análoga, pode-se afirmar que a dummy "home" capta o impacto das fronteiras estaduais - devido a isso chamar-se também "efeito fronteira intranacional" - e a variável dummy "Brasil" busca captar a importância da fronteira nacional para a determinação dos fluxos comerciais internacionais ou efeito fronteira internacional. Os dados utilizados englobam os fluxos comerciais entre 26 estados brasileiros ${ }^{11}$ e os fluxos internacionais de cada estado para 164 países, para 1991, 1997, 1998 e 1999. Segue abaixo a equação estimada em uma abordagem por efeitos fixos: 


$$
\operatorname{Ln} \frac{X_{i j}}{Y_{i} Y_{j}}=\beta_{0}+\beta_{1} \operatorname{LnDIST}_{i j}+\beta_{2} \text { Home }+\beta_{3} \text { Brasil }+\beta_{4} E_{i}+\varepsilon_{i j}
$$

em que:

$\mathrm{X}_{\mathrm{ij}}$ : exportações do estado “i” para o país ou estado " $\mathrm{j}$ ”;

$\mathrm{Y}_{\mathrm{w}}$ : PIB nominal dos estados ou países i e j;

DIST $_{\mathrm{ij}}$ : distância do estado i ao estado ou país j;

Home: variável dummy que assume valor 1 no caso do comércio seja entre cidades de um mesmo estado (intraestadual) e zero para o caso do comércio ser interestadual ou internacional;

Brasil: variável dummy que assume valor 1, caso o comércio seja entre os estados brasileiros, e valor zero, em todos os outros casos;

Ei: efeitos-fixos de exportação;

$\beta_{0}$ até $\beta_{5}$ são parâmetros que se esperam que tenham, à exceção de $\beta_{3}$, sinal positivo; $\varepsilon_{i j}$ : erro.

Os autores utilizam o antilogaritmo da diferença dos coeficientes das vari- áveis "home" e "Brasil" [exp(home-brasil) = bb] para medir o grau de fragmentação interna, ou, no sentido inverso, o nível de integração doméstica. $\mathrm{O}$ coeficiente $h b$ captura a preferência dos estados brasileiros pelo comércio consigo mesmo, e não com os demais estados do Brasil ou com um país estrangeiro. Assim, quanto maior é o valor de $h b$, maior é o nível de fragmentação doméstica, pois maior deverá ser a porção de comércio intraestadual da equaçấo. Para a variável "Brasil”, a sistemática é semelhante, isto é, quanto maior o seu valor, menor é a integração internacional, e maior é o impacto do efeito fronteira. Desta forma, pode-se comparar o engajamento dos estados no comércio doméstico e internacional.

Os resultados para o efeito fronteira intranacional (dummy "home") mostram que, em 1999, um estado brasileiro, depois de controlado para as variáveis do modelo gravitacional, negociava 11 vezes mais com ele mesmo do que com outra unidade federativa, enquanto, em 1991, esse número chegava a 19 vezes. Ou seja, com o passar dos anos, teria ocorrido 
${ }^{12}$ Ou seja, para 1999, os fluxos de comércio doméstico eram 33 vezes superiores aos fluxos de comércio internacionais, e, para 1991, o mesmo índice era de apenas 17 vezes. redução da preferência comercial intraestadual em benefício do comércio interestadual no Brasil, mas ele continuaria muito elevado quando comparado ao de outros países. Na tentativa de justificar esses resultados, os autores apontam alguns de seus possíveis determinantes, tais como alíquotas de tributos internos (ICMS) não uniformizadas para o comércio doméstico, diferenças culturais e na estrutura de suas economias e o padrão das compras governamentais dos estados. Para o efeito fronteira internacional (dummy "Brasil"), os resultados são surpreendentes. Em 1999, o viés doméstico dos fluxos de comércio, após controlar o tamanho das economias e a distância entre elas, é igual a 33, ao passo que, para o ano de 1991, é de apenas $17 .{ }^{12}$ Desta forma, os autores observam que os resultados apresentados para o Brasil contrariam aqueles esperados de acordo com a literatura econômica. Em um país como o Brasil, engajado no processo global de integração internacional, através da abertura comercial observada no decorrer da década de 1990 e a formação do Mercosul, a partir de 1991, esperava-se queda do efeito fronteira internacional.

Apesar de os autores não terem realizado o cálculo do efeito fronteira por regióes brasileiras, pode-se deduzi-lo valendo-se dos coeficientes estaduais do efeito fronteira internacional. Em geral, os estados das regióes Sul e Sudeste apresentam os menores custos de fronteira internacional, ou seja, menores impactos do efeito fronteira para a determinação dos fluxos comerciais para o exterior. Em 1999, o intervalo de variaçáo do coeficiente do efeito fronteira internacional dos estados do Norte vai de 6,2 até 10,3; para a região Nordeste, o intervalo é de 5,8 até 8. Para os estados do Sul e do Sudeste, o intervalo de variância apresenta amplitude menor, com limite inferior de 1,3 e limite superior de 4 . Com base nos resultados apresentados pelos autores, pode-se afirmar que os estados das regióes Sul e Sudeste são mais integrados internacionalmente que os das regiōes Norte e Nordeste. Além disso, aqueles estados mais integrados nacionalmente também o são internacionalmente. Estados da regiáo Norte, como Amapá e Acre, por exemplo, possuem elevado coeficiente do efeito fronteira intranacional, assim como alto coeficiente para o efeito fronteira internacional. Em contraposição, São Paulo, na região Sudeste, apresenta baixo coeficiente para o efeito fronteira, tanto para os fluxos domésticos quanto para os internacionais. $\mathrm{Na}$ prática, isso significa dizer que os estados que comercializam proporcionalmente mais internamente, ou seja, com os demais estados 
brasileiros, também tendem a comercializar mais com o exterior. ${ }^{13}$

Leusin Jr. e Azevedo (2009) buscaram mensurar o impacto do efeito fronteira para o Brasil e suas regióes, também através do uso do modelo gravitacional, utilizando dados de corte seccional para o ano de 1999, com todos os 27 estados brasileiros e 40 países. A conclusão principal é que as fronteiras ainda representam significativo custo de comércio para o Brasil, especialmente para as regióes Norte e Nordeste. Observou-se que, para o Brasil, em 1999, o impacto do efeito fronteira se traduz em um viés doméstico dos fluxos de comércio 33 vezes superior aos fluxos comerciais internacionais.

Esse resultado mostra-se muito semelhante aos encontrados por Silva et al. (2007), que encontraram um viés de 37 vezes, assim como o resultado encontrado por Daumal e Zignago (2005), de 32 vezes. Todos esses trabalhos analisaram o efeito fronteira para o Brasil, em 1999. O coeficiente do efeito fronteira apresenta grande variação entre as regiōes, indicando que as exportações intranacionais são entre cinco (região Sul) e 83 vezes (região Nordeste) maiores do que aquelas para os demais países. Vale notar que o efeito fronteira decresce significativamente do norte para o sul do país. Estados do Norte e do Nordeste apresentam efeito fronteira relativamen- te alto, se comparados com dados da literatura internacional. A grande parcela do comércio intranacional no comércio total dos estados das regióes Norte e Nordeste parece contribuir para um viés doméstico mais elevado para tais regióes. Além disso, a malha de transportes dessas regióes mostra-se mais precária, menos diversificada e mais distante do centro econômico do país do que das regióes Sul e Sudeste.

$\mathrm{Na}$ literatura brasileira que tange à temática do efeito fronteira regional, também se destaca o trabalho de Hidalgo e Vergolino (1998). Os autores discutem o fluxo de comércio do Nordeste para o resto do Brasil e exterior usando o modelo gravitacional. No estudo, eles procuraram avaliar, para o ano de 1991, a importância das fronteiras (internas e externas) sobre o padrão do comércio internacional e intranacional. Para tanto, usaram as exportaçóes de cada estado do Nordeste para cada um dos outros 26 esta- apresentaram impactos comparativamente mais significativos com a criação do Mercosul. Em relação ao bloco, uma série de trabalhos buscou estimar os efeitos do bloco sobre os fluxos de comércio intra e extrabloco (por exemplo, Kume; Piani, 2000; Sá Porto, 2002; Azevedo, 2004). 
dos da Federação e para cada um dos países com os quais os estados nordestinos mantinham comércio.

A fim de conhecer melhor o papel da existência de fronteiras para o comércio exterior da região Nordeste, os autores estimaram o modelo gravitacional em uma abordagem por MQO, usando a forma log-linear. Constataram que o efeito da existência das fronteiras sobre os fluxos de comércio são significativos, uma vez que as exportaçóes interestaduais representam para o Nordeste cerca de 11 vezes mais que as exportaçóes internacionais. Os autores mostram também que os fluxos de comércio interno na região Nordeste são 1,75 vez maior que as exportaçóes para as outras regióes do Brasil. A existência de fronteiras parece mostrar-se um determinante importante do comércio nordestino, principalmente a fronteira internacional. $\mathrm{Na}$ tentativa de justificar esses resultados, os autores argumentam que a produção da regiáo Nordeste é mais concentrada em bens primários e intermediários, e o seu comércio consiste basicamente na troca de bens agrícolas e matérias-primas por produtos manufaturados, caracterizando um comércio interindustrial.

Tahela 1_Consolidação dos resultados e variáveis utilizadas pelo modelo gravitacional

\begin{tabular}{|c|c|c|c|c|c|c|}
\hline Autores & Período & Região Analisada & $\begin{array}{l}\text { Dimensão do } \\
\text { Efeito fronteira }\end{array}$ & $N^{0}$ de obs. & Método & $\mathbf{R 2}$ \\
\hline McCallum (1995) & 1988 & (Canada-EUA) & 22 & 683 & MQO & 0,8 \\
\hline Helliwell (1996) & $1988-1990$ & (Canadá-EUA) & 20 & 677 & MQO & 0,8 \\
\hline \multirow[t]{2}{*}{ Anderson e Wincoop (2003) } & 1993 & (Canadá-EUA) & 16,4 & 589 & SUR & 0,7 \\
\hline & 1993 & (EUA-Canadá) & 1,5 & 589 & SUR & 0,8 \\
\hline Nitsch (2000) & $1979-1990$ & (EU - mundo) & 10 & 972 & SUR & 0,9 \\
\hline Gil-Pareja et al. (2005) & 1995-1998 & (regiōes espanholas-mundo) & 9 até 59 & 3808 & Efeitos fixos & 0,7 \\
\hline \multirow[t]{2}{*}{ Daumal e Zignago (2005) } & 1991 & (Brasil - mundo) & 17,04 & 2249 & Efeitos fixos & 0,7 \\
\hline & 1999 & (Brasil - mundo) & 32,55 & 2441 & Efeitos fixos & 0,7 \\
\hline \multirow[t]{2}{*}{ Hidalgo e Vergolino (1998) } & 1991 & (Nordeste - mundo) & 11,5 & 461 & MQO & 0,6 \\
\hline & 1991 & (Nordeste-Brasil) & 1,75 & 461 & MQO & 0,6 \\
\hline Silva et al. (2007) & 1999 & (Brasil - mundo) & 37,7 & 1334 & MQO & 0,7 \\
\hline Leusin e Azevedo (2009) & 1999 & (Brasil - mundo $)$ & $33,1$. & 1782 & MQO/ Tobit & 0,65 \\
\hline
\end{tabular}


Os trabalhos apresentados evidenciam que as fronteiras estaduais e nacionais ainda representam significativo custo adicional de comércio. Os resultados para o efeito fronteira brasileiro mostram-se muito semelhantes. Silva et al. (2007) encontraram um viés de comércio nacional de 37 vezes, ao passo que o resultado encontrado por Daumal e Zignago (2005) chegou a 32 vezes. Leusin Jr. e Azevedo (2009) encontraram um viés doméstico dos fluxos de comércio 33 vezes superior aos fluxos comerciais internacionais. Há uma série de justificativas para o elevado viés doméstico do comércio brasileiro, tais como o baixo grau de substituição entre produtos nacionais e estrangeiros, as elevadas barreiras ainda vigentes no comércio internacional, o tamanho do território e da população brasileira e a distância em relação aos principais mercados.

Um aspecto importante do efeito fronteira para as regiôes brasileiras é que a sua magnitude apresenta variação extremamente elevada entre as regióes, sendo significativamente maior nas regióes Norte e Nordeste em relação às Sul e Sudeste. A região Sul mostrou o menor viés doméstico de seus fluxos comerciais, indicando o maior grau de abertura dessa regiáo para o exterior. Dado o menor viés apresentado para a região Sul, na próxima seção busca-se mensurar a magnitude do efeito fronteira para esse dado, o único estado com informaçóes consolidadas para o período posterior a publicação de Vasconcelos (2001).

\section{3_D efeito fronteira para o Rio Grande do Sul}

A seção anterior apresentou uma revisão de literatura sobre o efeito fronteira, com ênfase no caso brasileiro. Notou-se a existência de forte viés intranacional do comércio brasileiro, mesmo após o processo de abertura comercial ocorrido nos anos 1990. O trabalho de Daumal e Zignago (2005) sugere inclusive que o viés doméstico dos fluxos comerciais brasileiros teria aumentado no decorrer da década de 90. Valendo-se dos resultados apresentados, é possível supor que haja um padrão para o efeito fronteira brasileiro para o ano de 1999, oscilando entre $32 \mathrm{e}$ 37 vezes. Esta seção busca calcular o efeito fronteira do Rio Grande do Sul, no período entre 1997 e 2002.

\section{1_Dados}

A variável dependente são as vendas do Rio Grande do Sul para os 26 estados da Federação e as exportações desse mesmo estado para os 46 países da amostra. O fluxo comercial do RS para os estados do Brasil, entre 1997 e 2002, foi obtido de 
Divisão de Estudos Econômicos (DEE) da Secretaria da Fazenda do Estado (2004), expresso em R \$ correntes. Os dados das vendas do RS para os estados brasileiros, entre 1997 e 2002, foram transformados em valores constantes de 2000, através do IPCA. ${ }^{14}$ As exportaçóes do RS para os países de amostra foram obtidos do site Aliceweb, do Ministério do Desenvolvimento, Indústria e Comércio Exterior (MDIC) em US\$ correntes. Para a atualização dos fluxos de comércio internacionais do RS, foi usado o indicador da inflaçáo americana ao consumidor. ${ }^{15} \mathrm{Com}$ esse procedimento, passam-se a ter os fluxos de comércio internacionais em dólares constantes para o ano de 2000, sendo convertidos para reais pela taxa de câmbio média do ano de 2000 (R\$/US\$ = 1,8302). Desta forma, obtêm-se os fluxos de comércio internacionais em reais constantes para o ano de 2000.

\footnotetext{
${ }^{14}$ Os dados terão como base

${ }^{16}$ A distância entre duas

o ano de 2000, uma vez que

cidades é medida de centro

o PIB para os países e para os

estados brasileiros geralmente

está disponível ou em

valores correntes ou a preços

constantes de 2000.

${ }^{15}$ Conhecida sob a

denominação; CPI

-All Items, (2005=100).
}

Os dados do Produto Interno Bruto (PIB) e do PIB per capita dos estados brasileiros encontravam-se a preços constantes de 2000, deflacionados pelo Deflator Implícito do PIB nacional, calculados pelo IBGE e obtidos no site do IPEADATA. Os dados dos países selecionados (PIB e PIB per capita em US\$ constantes de 2000) foram obtidos no banco de dados do Banco Mundial; para Taiwan e Coreia do Sul, os dados foram conseguidos no banco de dados do Fundo Monetário Internacional. O PIB e o PIB per capita dos países da amostra encontravam-se em dólares constantes para o ano de 2000, sendo necessária a conversão desses para reais de 2000 pela taxa de câmbio média anual desse ano.

A distância, medida em quilômetros, foi obtida no Departamento Nacional de Infraestrutura de Transportes (DNIT) e representa a distância física entre Porto Alegre e as capitais de cada estado. ${ }^{16}$ Para a distância entre Porto Alegre e os países da amostra, considerou-se aquela entre Porto Alegre e o principal porto de cada país da amostra, sendo esses dados extraídos do site Sea Distances - Voyage Calculator (http://e-ships.net/ dist.htm). ${ }^{17}$ Para a construção da amostra dos países importadores, foram considerados alguns critérios seguidamente usados na literatura, tais como ampla 
abrangência geográfica, considerando no mínimo um país para cada continente e elevada participação no comércio total, contendo ao menos $80 \%$ do total das exportaçóes para os períodos pesquisados. ${ }^{18} \mathrm{~A}$ amostra selecionada inclui $46 \mathrm{pa}$ íses, contemplando ambos os critérios. As exportações para os países da amostra representam $91 \%$ das exportaçóes do Rio Grande do Sul, entre 1997 e 2002, e abrange todos os continentes. ${ }^{19}$

\section{2_Abordagem econométrica}

Para este estudo, o modelo a ser utilizado estabelece as variáveis tradicionais anteriormente citadas como aquelas que procuram captar os efeitos da adjacência e da similaridade da renda no padráo de comércio entre os parceiros comerciais. Assim, a forma da equação gravitacional aplicada ao comércio nacional e internacional utilizada para a estimação do efeito fronteira do Rio Grande do Sul, baseada em Silva et al. (2007), é expressa como:

$$
\begin{aligned}
& \operatorname{Ln} X_{i j}=\beta_{0}+\beta_{1} \operatorname{Ln} Y_{i}+\beta_{2} \operatorname{Ln} Y_{j}+ \\
& \quad+\beta_{3} \operatorname{LnDIST}_{i j}+\beta_{4} F C+\beta_{5} A_{d j}+ \\
& +\beta_{6} \operatorname{Ln}\left(P P C_{i}-P P C_{j}\right)^{2}+\varepsilon_{i j}
\end{aligned}
$$

onde:

$\mathrm{X}_{\mathrm{ij}}$ : vendas nacionais e exportaçóes do $\mathrm{RS}$ para o estado ou o país j;
$\mathrm{Y}_{\mathrm{w}}$ : PIB dos estados ou dos países i e j;

Dist $t_{\mathrm{ij}}$; distância em km de Porto Alegre ao estado ou ao país j;

FC: uma variável "dummy" que assume o valor 1 , se as vendas do RS vão para o estado j do Brasil, e zero, se elas têm como destino outro país;

Adj: uma variável “dummy” que assume o valor 1 , se as vendas do RS vão para um estado ou um país adjacente, e zero, caso contrário;

$\left(\mathrm{PPC}_{\mathrm{i}}-\mathrm{PPC}_{\mathrm{j}}\right)^{2}$ : quadrado da diferença entre o PIB per capita do RS e o PIB per capita dos estados ou dos países da amostra; $\beta_{0} 0$ a $\beta_{6}$ são parâmetros com sinais positivos, à exceção de $\beta_{3}$ e $\beta_{6}$;

$\varepsilon_{i j}$ : erro.

O modelo foi inicialmente estimado por meio de Mínimos Quadrados Ordinários (MQO), seguindo uma especificação log-linear, o que permite interpretar os coeficientes como elasticidades e se baseia em uma amostra de dados agrupados (pooled data), referentes ao período entre 1997 e 2002, do Rio Grande do Sul, dos demais estados brasileiros e de 46 países, obtendo dessa forma 432 observaçóes (6 anos x(26 estados + 46 países)). Na medida em que não houve dados censurados para a variável endógena (exportaçóes do Rio Grande do
${ }^{18}$ Ver McCallum (1995) e Sá Porto (2002).

${ }^{19}$ A lista completa dos países está em anexo. 
Sul para os demais estados e países), não foi preciso empregar o modelo Tobit. A vantagem de se combinar os dados em uma única equação (regressão combinada), em relação à opção de se usar dados em corte transversal, refere-se à obtenção de estimativas dos parâmetros mais confiáveis, bem como aliviar o problema de multicolinearidade, dar mais grau de liberdade e maior eficiência. Essas características são particularmente importantes quando se busca estimar coeficientes do efeito fronteira considerando-se apenas um estado exportador.

Também foi realizado um exercício estatístico estruturado em dados em painel, que se utiliza de três estimadores diferentes. Na primeira especificação, é aplicado o estimador de Mínimo Quadrado Ordinário clusterizado (Pooled Cluster). Já a segunda estrutura impóe um modelo hierárquico, tal que, na equação de $1^{\circ}$ nível, se aplica o estimador de efeito fixo, e a equaçáo de $2^{\circ}$ nível é organizada sobre a metodologia de dados de corte. Por fim, a última particularização emprega o estimador de efeito aleatório.

O método de Mínimos Quadrados clusterizados permite estimar parâmetros eficientes mesmo quando se encontra entre as variáveis independentes do modelo considerado componentes in- variantes no tempo. O estimador de efeito fixo "puro" apresenta multicolinearidade perfeita entre o efeito individual e aquelas variáveis independentes invariantes no tempo, problema que é superado ao se construir um modelo hierárquico. Em geral, um modelo hierárquico acaba por estabelecer certa ordem na estimação dos coeficientes. Isto é, uma estrutura hierárquica prescreve unidades individuais, em um $1^{\circ}$ nível, agrupadas em unidades maiores, em um $2^{\circ}$ nível, e assim sucessivamente. No caso específico do modelo estimado neste artigo, sugere-se uma arquitetura hierárquica que combine componentes variantes no tempo e entre as regióes no $1^{\mathrm{o}}$ nível (dados em painel) com componentes variantes apenas entre as regióes no $2^{\circ}$ nível (cross-section). Ou seja:

$$
\begin{gathered}
Y_{i, t}=\sum_{k=1}^{K} \beta_{k} \cdot X_{k, i, t}+\mu_{i}+v_{i, t} \\
\mu_{i}=\gamma_{0}+\sum_{j=1}^{J} \gamma_{j} \cdot Z_{j . i}+e_{i}
\end{gathered}
$$

Assim, $Y_{i, t}$ representa a variável dependente do modelo hierárquico; nesse caso, a corrente de comércio do Rio Grande dos Sul com os parceiros selecionados. Por sua vez, o componente $X_{k, i, t}$ 
indica o conjunto de variáveis que apresenta variação em "i” e "t"; PIB do Rio Grande do Sul; PIB do parceiro comercial desse estado; e PIB per capita. O vetor $Z_{j, i}$ representa todas as $j$ variáveis que não variam no tempo: distância, efeito adjacência e efeito fronteira. Nesse sentido, no $1^{\circ}$ nível tem-se uma estrutura de dados em painel, já no $2^{\circ}$ nível, proporciona-se um modelo de dados de corte puro. A estrutura hierárquica de $2^{\circ}$ nível encaixa-se no processo de geração de dados referente ao efeito individual estimado no $1^{\circ}$ nível. Já o estimador de efeito aleatório não identifica o problema da multicolinearidade perfeita entre o efeito individual e os componentes invariantes no tempo. Salienta-se ainda que todas as estimativas foram geradas controlando a autocorrelação e a heterocedasticidade nos resíduos. Ou seja, é empregado um estimador robusto.

\section{3_Resultados}

$\mathrm{Na}$ Tabela 2, são apresentadas as principais estimativas obtidas para o modelo de comércio do Rio Grande do Sul. Na primeira coluna, são mostrados os resultados da estimação em sua forma mais simples, excluindo as variáveis adjacência e similaridade de renda (equação 1), sendo a versão mais simples do modelo, sem as variáveis adjacência e similaridade de renda. Na segunda coluna (equação 2), vê-se a versão do modelo com a inclusão da variável adjacência e sem a variável similaridade de renda. $\mathrm{Na}$ terceira coluna (equação 3), mostra-se a versão do modelo com a inclusão da variável similaridade de renda e sem a variável adjacência. Na quarta coluna (equação 4), é apresentada a versão completa do modelo da equação gravitacional, incluindo todas as variáveis que constam na equação 3. Tradicionalmente, os modelos gravitacionais baseados em dados agrupados, que analisaram o efeito fronteira, apresentaram heterocedasticidade. Em virtude desse histórico, o presente trabalho considera a iminência de violação das condições para que se obtenha o melhor estimador não viesado (MELNV). O teste de White confirmou a existência de heterocedasticidade e, desta forma, o modelo foi corrigido pelo método de White para todas as estimaçóes via MQO.

De maneira geral, os resultados foram muito bons, especialmente quando se considera aqueles com a especificação mais completa (equação 4), com as variáveis consideradas explicando mais de 69\% das variaçóes nas exportações estaduais, em que todos os parâmetros estimados são estatisticamente significantes, em sua maioria ao nível de probabilidade de $1 \%$. As mudanças ocorridas nos estimadores em virtude da exclusão das variáveis adjacên- 
Tabela 2_Estimativas do modelo gravitacional para o Rio Grande do Sul, entre 1997 e 2002

\begin{tabular}{|c|c|c|c|c|}
\hline Variável Independente & (i) & Equa & $\begin{array}{l}\text { soes } \\
\text { (3) }\end{array}$ & (4) \\
\hline \multirow[t]{2}{*}{ Constante } & $-79,70^{* *}$ & $-80,72^{* * *}$ & $-79,32^{* * *}$ & $-80,34^{* * *}$ \\
\hline & $(39,34)$ & $(36,63)$ & $(36,48)$ & $(33,57)$ \\
\hline \multirow[t]{2}{*}{$\log (\mathrm{PIBi})$} & $3,25^{* *}$ & $3,27^{* * *}$ & $3,22^{* * *}$ & $3,24^{* * *}$ \\
\hline & $(1,56)$ & $(1,45)$ & $(1,45)$ & $(1,33)$ \\
\hline \multirow[t]{2}{*}{$\log (P I B j)$} & $0,81^{*}$ & $0,80^{*}$ & $0,89^{*}$ & $0,89^{*}$ \\
\hline & $(0,03)$ & $(0,03)$ & $-0,03$ & $(0,03)$ \\
\hline \multirow[t]{2}{*}{ Log (DISTij) } & $-0,33^{*}$ & $-0,28^{*}$ & $-0,30^{*}$ & $-0,25^{*}$ \\
\hline & $(0,04)$ & $(0,04)$ & $(0,04)$ & $(0,03)$ \\
\hline \multirow[t]{2}{*}{$\log (P P C i-P P C j)$} & & & $-0,12^{*}$ & $-0,12^{*}$ \\
\hline & & & $(0,01)$ & $(0,01)$ \\
\hline \multirow[t]{2}{*}{ Dummy Adj } & & $1,99 *$ & & $2,00^{*}$ \\
\hline & & $(0,16)$ & & $(0,17)$ \\
\hline \multirow[t]{2}{*}{ Dummy FC } & 0,28 & $0,66^{* * *}$ & 0,34 & $0,73^{* *}$ \\
\hline & $(0,36)$ & $(0,35)$ & $(0,30)$ & $(0,27)$ \\
\hline R2 Ajustado & 0,5745 & 0,6351 & 0,6336 & 0,6954 \\
\hline Teste F & 146,50 & 151,08 & 150,10 & 165,06 \\
\hline Num. Obs. & 432 & 432 & 432 & 432 \\
\hline Método Est. & MQO & MQO & MQO & MQO \\
\hline
\end{tabular}

Os valores entre parênteses são os erros-padrăo das estimativas.

*Significância no nível de $1 \%$.

**Significância no nível de $5 \%$.

***Significância no nível de $10 \%$. cia e/ou similaridade de renda mostram a importância do uso da especificação completa do modelo. A inclusão da dummy adjacência ocasionou queda marginal no coeficiente da variável distância, o que era esperado e coerente com a literatura internacional. Já a inclusão da variável de similaridade de renda gerou elevação da significância do PIB do país/estado importador para a determinação do fluxo de comércio entre as partes.

Os resultados mostram que a elasticidade das exportaçóes em relação ao PIB do estado exportador se situa ligeiramente acima de 3,2 e é significativamente maior que a elasticidade das exportaçóes em relação ao PIB do estado ou país importador, que se situa em torno de 0,9. Ou seja, os resultados parecem mostrar que o PIB do estado exportador explica em maior grau o volume de comércio entre os estados ou os países. Além disso, a elasticidade do comércio bilateral com relação às rendas dos países é bastante elevada e razoavelmente estável independentemente da especificação utilizada.

Em geral, um aumento de $1 \%$ no PIB dos estados ou dos países importadores implica um crescimento de 3,2\% das exportaçóes do Rio Grande do Sul. Na literatura empírica que envolve o efeito fronteira, é corriqueira a observação de que a elasticidade das exportaçóes em relação ao PIB do estado/país exportador seja superior à elasticidade das exportações em relação ao PIB do estado/país importador. Ou seja, tradicionalmente a renda do estado/país exportador explica em maior grau o volume exportado entre dois parceiros do que a renda do estado/país importador. 
A proximidade dos valores estimados para o coeficiente relacionado à variável distância reflete a robustez das estimativas. A elasticidade das exportações em relação à distância é negativa e se situa em torno de 0,3 , com elevado grau de significância estatística. $\mathrm{O}$ coeficiente estimado da distância absoluta demonstra sua importância como fator de resistência ao comércio: o acréscimo de $1 \%$ na distância entre o RS e seus parceiros comerciais acarreta queda de $0,3 \%$ no comércio entre eles.

A estimação do efeito adjacência no comércio está indicada na segunda e quarta colunas por coeficientes que se situam em torno de 2 e apresentam significância no nível de $1 \%$. Mantendo-se constantes as demais variáveis, esses valores indicam que o comércio de um estado com outro adjacente é, em média, 7,4 vezes maior que as exportaçóes para aqueles estados que não têm fronteira em comum. A magnitude desse re- sultado é surpreendente, dada a inexistência conceitual de barreiras tarifárias, mas que encontra alguma explicação na extensão territorial do Brasil e nas dificuldades de transporte entre os estados, principalmente para os estados do Norte e do Nordeste do país. ${ }^{20}$

A hipótese frequentemente usada em modelos gravitacionais de que os estados ou os países com renda per capita semelhantes tendem a comercializar mais entre si do que aqueles estados ou países com renda per capita diferentes foi testada com a inclusão da variável similaridade de renda. ${ }^{21}$ Observa-se que o valor encontrado para o coeficiente foi negativo, conforme esperado, e estatisticamente significativo, porém muito inelástico, indicando que, para o Rio Grande do Sul, a hipótese de Linder não é tão relevante.

A especificação completa do modelo mostra que o coeficiente da variável dummy FC, que mede o efeito fronteira do Rio Grande do Sul, foi significati-

\footnotetext{
${ }^{20} \mathrm{Na}$ prática as diferentes alíquotas do ICMS (Imposto sobre Circulação de Mercadorias e Serviços) existentes entre os estados brasileiros acabam por criar um tipo alternativo de barreira tarifária.
}

\author{
${ }^{21}$ Tradicionalmente, \\ muitas teorias do comércio \\ internacional enfatizam a \\ ótica da oferta para explicar \\ o padráo do comércio \\ internacional. A Hipótese \\ de Linder (1961) implica \\ que o padrão de comércio \\ bilateral é determinado pela \\ similaridade de renda entre
}

\author{
os países. Ou seja, países \\ de renda alta tenderiam a \\ comercializar com países de \\ renda semelhante, e países de \\ renda baixa apresentariam \\ propensão maior de \\ comercializar com países de \\ renda baixa. Resumidamente, \\ pode-se dizer que as hipóteses \\ de Linder são as que seguem:
} a demanda é um importante determinante do comércio; a demanda doméstica determina qual a variedade de produtos que o país vai produzir, e a variedade de produtos produzidos por um país será exportada principalmente para países com demanda similar. 
vo, com valor de 0,73 . O coeficiente encontrado para o efeito fronteira significa que, ceteris paribus, as exportaçóes do Rio Grande do Sul para os demais estados brasileiros é cerca de duas vezes maior do que as exportaçóes do estado para o exterior. É importante salientar o menor valor encontrado para o efeito fronteira do Rio Grande do Sul, no período examinado, com os observados na literatura para o país, bem como para os estados e as regiōes brasileiras. De acordo com Sil- va et al. (2007), o efeito fronteira do Brasil em 1999 era de 37,7 vezes, ao passo que, para Daumal e Zignago (2005), ele chegava, em 1999, a 32,5 vezes. Já para a região Sul, o efeito fronteira chegou a 5 vezes, em 1999, para Leusin Jr. e Azevedo (2009), enquanto Daumal e Zignago (2005) encontraram um viés doméstico para o Rio Grande do Sul, em 1999, de 22 vezes, muito acima daquele encontrado neste artigo.

\section{Gráfico 1_Relação exportações/vendas internas em 1999}

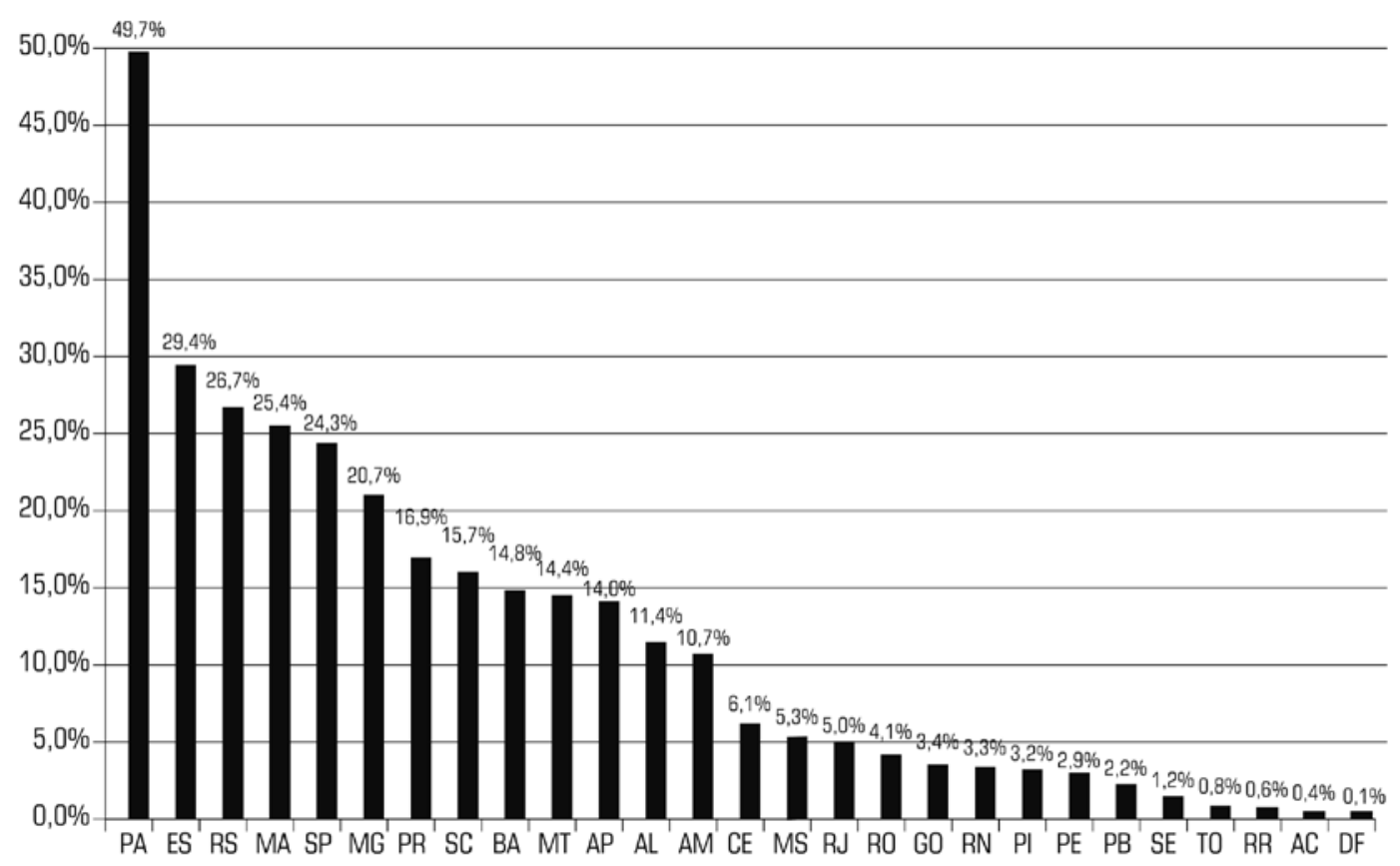


Embora os trabalhos utilizem períodos e abordagens econométricas diferentes, tal resultado para o Rio Grande do Sul chama a atenção. Esse fenômeno reflete a grande propensão do estado a exportar, captado pelo modelo gravitacional. Conforme mostra o Gráfico 1, o valor das exportações do estado em relação às vendas para os demais estados brasileiros chegou a $26,7 \%$ em 1999, sendo o estado com a terceira maior relação no país, somente atrás do Pará e do Espírito Santo. A partir de 1991, o estado se beneficiou de sua posição geográfica para elevar suas vendas aos parceiros do Mercosul. Considerando-se a participação das exportaçóes dos estados para o bloco em relação às exportações totais do país, observa-se que o Rio Grande do Sul ocupa a segunda posição. No estado, as exportaçóes para o Mercosul representam 1,22\% das exportaçóes totais do país, superado apenas por São Paulo, onde essa relação é de 6,16\%.

Dada a discrepância dos resultados encontrados na literatura, conforme observado acima, também foram realizadas estimaçóes baseadas em dados em painel, mediante três estimadores diferentes. Conforme mencionado na seção anterior, na primeira especificação é aplicado o estimador de Mínimo Quadrado Ordinário clusterizado. Já a segunda estrutura emprega o estimador de efeito aleatório, enquanto a última particularização impõe um modelo hierárquico, tal que, na equação de $1^{\circ}$ nível, se aplica o estimador de efeito fixo, e a equação de $2^{\circ}$ nível é organizada sobre a metodologia de dados de corte.

Os resultados das estimaçóes em painel são apresentados na Tabela 3. Percebe-se que os coeficientes relacionados ao PB do país importador, da distância e da adjacência apresentam os valores esperados, sendo significativos e muito semelhantes nas três estimações realizadas, bem como aqueles obtidos nas estimações em MQO (Tabela 2). Os valores do coeficiente relacionado ao PIB do país exportador, no entanto, mostram queda significativa nas três estimações, variando entre 1,2 e 1,3, quando comparados às estimaçóes via MQO. Esse resultado pode indicar que parte do efeito do PIB do país exportador, estimado por MQO, estava atrelado ao efeito individual, respeitando um modelo de dados em painel.

Uma mudança fundamental em relação às estimaçôes através do MQO se refere ao coeficiente relacionado ao efeito fronteira do Rio Grande do Sul. Nas três estimações, o seu valor não foi significativo, sinalizando que as exportaçóes para os demais estados brasileiros não seriam superiores àquelas destinadas aos países da amostra, quando se emprega a análise ba- 
Tabela 3_Estimativas do modelo gravitacional para o Rio Grande do Sul, entre 1997 e 2002

\begin{tabular}{|c|c|c|c|}
\hline Variável Independente & MQ0 Clusterizado & $\begin{array}{c}\text { Métodos . . . } \\
\text { Efeito Aleatório }\end{array}$ & $\begin{array}{l}\text { Efeito Fixo } \\
\text { Hierárquico }\end{array}$ \\
\hline \multirow[t]{2}{*}{ Constante } & $-31,27^{*}$ & $-28,07^{*}$ & $-30,15^{*}$ \\
\hline & $(6,44)$ & $(3,94)$ & $(3,96)$ \\
\hline \multirow[t]{2}{*}{$\log (\mathrm{PIBi})$} & $1,32^{*}$ & $1,19^{*}$ & $1,23^{*}$ \\
\hline & $(0,27)$ & $(0,17)$ & $(0,24)$ \\
\hline \multirow[t]{2}{*}{$\log (\mathrm{PIBj})$} & $0,84^{*}$ & $0,80^{*}$ & $0,68^{*}$ \\
\hline & $(0,07)$ & $(0,06)$ & $(0,12)$ \\
\hline \multirow[t]{2}{*}{ Log (DISTij) } & $-0,28^{*}$ & $-0,28^{*}$ & $-0,26^{* *}$ \\
\hline & $(0,10)$ & $(0,07)$ & $(0,10)$ \\
\hline \multirow[t]{2}{*}{$\log (P P C i-P P C j)$} & $-0,09^{* *}$ & $-0,03^{* * *}$ & 0,02 \\
\hline & $(0,04)$ & $(0,02)$ & $(0,03)$ \\
\hline \multirow[t]{2}{*}{ Dummy Adj } & $1,96^{*}$ & $2,01^{*}$ & $2,07^{*}$ \\
\hline & $(0,32)$ & $(0,32)$ & $(0,31)$ \\
\hline \multirow[t]{2}{*}{ Dummy FC } & $-0,69$ & 0,15 & 0,90 \\
\hline & $(0,82)$ & $(0,62)$ & $(0,88)$ \\
\hline R2 Ajustado & 0,6990 & 0,6876 & 0,1259 \\
\hline Teste Wald & $110,08^{* * * *}$ & 732,38 & 204,80 \\
\hline Num. Obs. & 432. & 432 & 432. \\
\hline
\end{tabular}

Os valores entre parêntesis são os erros padrão das estimativas.

*Significância no nível de $1 \%$.

${ }^{*}$ Significância no nível de 5\%.

***Significância no nível de $10 \%$.

**** A estatística refere-se ao teste $\mathrm{F}$.

OBS: A estatística F e o $\mathrm{R}^{2}$ ajustado para o modelo de dados de corte foram 125,65 e 0,7463, respectivamente. seada em dados em painel. Ou seja, o efeito fronteira não ocorreria no Rio Grande do Sul. Esse resultado estatístico remete a maior proximidade geográfica do estado de outros países, principalmente do Mercosul, corroborado pelo sinal negativo estimado para o parâmetro associado a distância. Não obstante a questão geográfica, a relação comercial entre o estado e o Mercosul se beneficia também de um acordo tarifário. Ademais, o estado tem maior propensão à exportaçấo de produtos primários, que são mais direcionadas para países do que para os demais estados brasileiros, seguindo um padrão bem explicado pelas vantagens comparativas do estado, e ambos os fenômenos estariam sendo mais adequadamente captados pela estimação por meio de dados em painel.

\section{4_Conclusão}

O Rio Grande do Sul tem se destacado como importante estado exportador brasileiro. Este artigo buscou mensurar o impacto do efeito fronteira para o Rio Grande do Sul, no período 1997-2002, considerando-se as exportaçóes do estado e as vendas internas a outros estados brasileiros. A forma usual de se estimar o efeito fronteira é por meio do modelo gravitacional, que, além das variáveis convencionais, como PIB e distância absoluta, inclui 
uma variável dummy associada ao comércio intranacional e/ou internacional. Essa dummy indica se o fato de o fluxo de comércio necessitar cruzar fronteiras regionais ou nacionais tem alguma influência sobre o padrão de comércio de um estado e/ou de um país.

Os resultados estimados pelo método dos Mínimos Quadrados Ordinários indicaram que as fronteiras representam custo significativamente menor para as exportações do Rio Grande do Sul em relação ao país e a outras regióes brasileiras. Observou-se que, para o estado, o impacto do efeito fronteira se traduz em um viés doméstico do fluxo comércio apenas duas vezes superior aos fluxos comerciais internacionais. Tal resultado mostra-se muito inferior aos encontrados para o Brasil, em 1999, por Silva et al. (2007), que encontraram um viés de 37 vezes, assim como o resultado apurado por Daumal e Zignago (2005) de 32 vezes. O efeito fronteira do Rio Grande do Sul estimado neste artigo também é inferior ao estimado para a região Sul do país por Leusin Jr. e Azevedo (2009), que chegou a cinco vezes, bem como aquele estimado para o estado por Daumal e Zignago (2005), que chegou a 22 vezes.

A estimação baseada em dados em painel não apenas confirmou o menor viés doméstico das exportaçôes do estado, como também mostrou não haver viés algum. Através do estimador de Mínimo Quadrado Ordinário clusterizado, do estimador de efeito aleatório, e de um modelo hierárquico, que na equação de $1^{\circ}$ nível aplica-se o estimador de efeito fixo e a equação de $2^{\circ}$ nível é organizada sobre dados de corte, o valor do efeito fronteira não foi significativo, sinalizando que as exportações para os demais estados brasileiros náo seria superior àquelas destinadas aos países da amostra. Isto é, o efeito fronteira não ocorreria no Rio Grande do Sul.

Embora os trabalhos utilizem períodos e abordagens econométricas diferentes, tal resultado para o Rio Grande do Sul reflete a grande propensão do estado a exportar, captado pelo modelo gravitacional. O valor das exportaçóes do estado em relação às vendas para os demais estados brasileiros chegou a 26,7\% em 1999, sendo o estado com a terceira maior relação no país. A partir de 1991, o estado também se beneficiou de sua posição geográfica para elevar suas vendas aos parceiros do Mercosul, levando-o a apresentar a segunda posição na participação das exportações dos estados para o bloco em relação às exportaçóes totais do país.

Esse resultado estatístico também pode ser explicado pela maior proximidade geográfica do estado com outros 
países, principalmente os do Mercosul, corroborado pelo sinal negativo estimado para o parâmetro associado a distância. Além disso, o estado apresenta maior propensão à exportação de produtos primários, que são mais direcionadas para países do que para os demais estados brasileiros, seguindo um padrão bem explicado pelas vantagens comparativas, e ambos os fenômenos, geográficos e econômicos, estariam sendo mais adequadamente captados pela estimação por meio de dados em painel. 


\section{Referências bibliográficas}

ANDERSON, J.; WINCOOP,

E. Gravity with gravitas:

A solution to the border puzzle. The American Economic Review, v. 93, p. 170-192, 2003.

AZEVEDO, A. O efeito do

Mercosul sobre o comércio:

Uma análise com o modelo

gravitacional. Pesquisa e

Planejamento Econômico,

v. 34, p. 307-339, 2004.

BALDWIN, R.; MARTIN, P.

Two waves of globalization:

Superficial similarities,

fundamental differences. National

Bureau of Economic Research.

Working Paper, v. 6.904, n. 1, p.

30. 1999. Disponível em: <http://

www.nber.org/papers/w6904.pdf>.

DAUMAL, M.; ZIGNAGO, S.

The border effects in Brazil. 2005.

Disponível em: < http://www.

dauphine.fr/globalisation/

daumal2.pdf $>$.

DEE (Departamento de

Estudos Tributários). Balança

Comercial Interestadual dos

Contribuintes do ICMS e Grau

de Abertura Econômica do

Rio Grande do Sul - 1997-2002.

Estudos Econômico-Fiscais, Ano

$10-\mathrm{n}^{\circ} 47,2004$. Disponível

em: <http://www.sefaz.

rs.gov.br/Site/MontaArquivo.

aspx?al=1_bal_com>.
DNIT, 2007. Departamento Nacional de Infraestrutura de Transportes. Disponível em: <http://wwwl.dnit.gov.br/ rodovias/distancias/distancias. asp>. Acesso em: 23 dez. 2007.

FRANKEL, J. Regional Trading blocs in the world economic system. Washington: Institute for International Economics, 1997.

GIL-PAREJA S.; LLOREA-

VIVEIRO R.; MARTINEZ-

SERRANO J.; OLIVER-ALONSO J.

The border effect in Spain.

The World Economy, v. 28,

p. 1617-31, 2005.

HELLIWELL, J. How much do national borders matter? Washington D.C.: Brookings Institution Press, v. 156, 1998.

HIDALGO, A.; VERGOLINO, J.

$\mathrm{O}$ nordeste no comércio inter-regional e internacional:

Um teste dos impactos por meio do modelo gravitacional. Economia Aplicada,

v. 2, p. 707-725, 1998.

KUME, H.; PIANI, G. Fluxos bilaterais de comércio e blocos regionais: Uma aplicação do modelo gravitacional. Pesquisa e Planejamento Econômico, v. 30, p. 1-21, 2000.
LEUSIN Jr., S.; AZEVEDO, A.

$\mathrm{O}$ efeito fronteira das regióes brasileiras: Uma aplicação do Modelo Gravitacional. Revista de Economia Contemporânea, v. 13, p. 229-258, 2009.

LINDER, S. An essay on trade and transformation. New York: John Wiley, 1961.

McCALLUM, J. National borders matter: Canada-US regional trade patterns. American Economic Review, v. 85, p. 615-623, 1995.

MDIC. Ministério do Desenvolvimento, Indústria e Comércio Exterior. Sistema de Análise das Informaçōes de Comércio Exterior. 2008.

MOREIRA, M.; CORREA, P. Abertura comercial e indústria: $\mathrm{O}$ que se pode esperar e o que se vem obtendo. Revista de Economia Política, São Paulo, v. 17, p. 61-91, 1997.

NITSCH, V. National borders and international trade: Evidence from the European Union. Canadian Journal of Economics, v. 33, p. 1091-1105, 2000.
OBSTFELD M.; ROGOFF K. the six major puzzles in international macroeconomics: Is there a common cause? NBER Working Paper, 7777, 2000. Disponível em: <http://nber15.nber.org/papers/ w7777. Acesso em: jan. 2011.

OHMAE, K. The borderless world: Power and strategy in the interlinked economy. New York: Harper Business, 1990.

OMC. Organização Mundial de Comércio. Estatísticas do Comércio Internacional 2010. Disponível em: <http://www.wto. org/>. Acesso em: jan. 2011.

SÁ PORTO, P. Mercosul and regional development in Brazil: A gravity model approach. Revista Estudos Econômicos, v. 32, p. $125-153,2002$.

SILVA, O.; ALMEIDA, F.; OLIVEIRA, B. Comércio internacional " $x$ " intranacional no Brasil: Medindo o efeitofronteira. Nova Economia, v. 17, p. 427-439, 2007.

SOUZA, Nali J. Abertura comercial e crescimento dos estados brasileiros, 1991/2000. Teoria e Evidência Econômica, v. 11, n. 21, p. 41-61, nov. 2003. 
RODRIGUEZ, Francisco.

Openness and growth: What have we learned? DESA Working Paper n'. 51, 2007.

VASCONCELOS, J. Matriz de fluxo do comércio interestadual no Brasil - 1999. Rio de Janeiro: IPEA, ago. 2001. (Texto para Discussão, 817).

VASCONCELOS, José Romeu; OLIVEIRA, Márcio Augusto. Análise da matriz por atividade econômica do comércio interestadual no Brasil-1999. Rio de Janeiro: IPEA, 2006. (Texto para Discussão no 1159).

\begin{tabular}{|c|}
\hline E-mail de contato dos autores: \\
\hline leusin01@gmail.com. \\
\hline aazevedo@unisinos.br. \\
\hline mlelis@unisinos.br. \\
\hline $\begin{array}{l}\text { Artigo recebido em agosto de } 2010 \text { e } \\
\text { aprovado em junho de } 2011\end{array}$ \\
\hline
\end{tabular}


Anexo 1

Países da amostra

\begin{tabular}{|c|c|}
\hline Angola & Holanda \\
\hline Argentina & Nigéria \\
\hline Austrália & Noruega \\
\hline Bélgica & Paraguai \\
\hline Bolívia & Peru \\
\hline Canadá & Filipinas \\
\hline Chile & Portugal \\
\hline China & Porto Rico \\
\hline Colômbia & Rússia \\
\hline República Dominicana & Arábia Saudita \\
\hline Equador & Cingapura \\
\hline Egito & África do Sul \\
\hline França & Espanha \\
\hline Alemanha & Suécia \\
\hline Hong Kong, China & Suíça \\
\hline Índia & Tailândia \\
\hline Indonésia & Taiwan \\
\hline Irã & Turquia \\
\hline Itália & Emirados Árabes Unidos \\
\hline Japão & Reino Unido \\
\hline Coreia do Sul & Estados Unidos \\
\hline Malásia & Uruguai \\
\hline México & Venezuela \\
\hline
\end{tabular}

